\title{
NUMERICAL SIMULATION OF HEAT TRANSFER PROBLEM FOR LAYERED GYPSUM PRODUCTS EXPOSED TO FIRE
}

\author{
Aivars Aboltins ${ }^{1}$, Harijs Kalis ${ }^{2}$, Kristaps Pulkis ${ }^{1}$, Juris Skujans ${ }^{1}$ \\ ${ }^{1}$ Latvia University of Life Sciences and Technologies, Latvia; \\ ${ }^{2}$ Institute of Mathematics and Computer Science, University of Latvia, Latvia \\ aivars.aboltins@inbox.lv, kalis@lanet.lv, k.pulkis@gmail.com, juris.skujans@1lu.lv
}

\begin{abstract}
The problem of heat transfer through layered material of gypsum board products exposed to fire is studied in the paper. This paper proposes a thermal nonlinear conductivity model in different gypsum product layers for foam gypsum plate (density $300 \mathrm{~kg} \cdot \mathrm{m}^{-3}$ ) and gypsum board (density $1000 \mathrm{~kg} \cdot \mathrm{m}^{-3}$ )with high temperatures. The specific heat and thermal conductivity coefficients depend on temperature. These types of connection are obtained using approximation by cubic splines. The 1-D nonlinearparabolic type partial differential equation (PDE), expressing the rate of the change of temperature in every layer, is derived for heat transfer. The approximation and calculation of corresponding initial boundary value problem is based on the Matlab solver "pdepe". The results of calculations are presented for one, two and three layered environment. The results of calculations are compared with the experiments at the Faculty of Environment and Civil Engineering of the Latvia University of Life Sciences and Technologies.
\end{abstract}

Keywords: gypsum board, foam gypsum, heat distribution, Matlab.

\section{Introduction}

Gypsum plaster is applied in building along with other cementitious materials as cement and lime. Gypsum boards are widely used for interior as walls or ceilings. This material is easy to produce, it is friendly, it has good sound isolation and it is easy to use, it has low price and etc. Gypsum has also a good fire resistance property. Thermal properties such as thermal conductivity and specific heat of gypsum boards were studied extensively [1-3]. The effect of void fraction and dehydration on thermal physical properties of gypsum board was investigated [4].

New composite materials with good properties as thermal insulators at elevated temperatures are developed in building construction. One of these materials is foam gypsum [5;6]. This is a material with less density as gypsum board. Commercial gypsum boards are widely used in the building industry as facing materials for walls and ceilings. Thermal response of gypsum materials has been experimentally and numerically studied during the past years [1-11]. Materials based on gypsum are known for excellent properties in fire protection and are used as general materials to protect building structures against fire. A very important role here is played by the heat transfer processes in the same material. It is much more important to determine the distribution of temperatures in a layered environment, with gypsum materials with different physical properties such as density. Experimentally it is very difficult to determine, therefore, the heat transfer process of mathematical modelling is used. There are several computation models made to predict the thermal behaviour of gypsum boards and foam gypsum under high heat conditions. These models investigate the gypsum layer with the same physical properties. They revealed the significance of using appropriate physical properties for simulating the temperature evolution inside a gypsum board when exposed to fire conditions [12-15]. As noted, "no significant influence of vapour transport on temperature is observed, when the phase change is omitted" [15].

The aim of the present research is to develop a mathematical model of heat transfer thought the layered material of gypsum with different densities (foam gypsum and gypsum board) at high temperature (similar to fire) on one of the walls.

\section{The mathematical model}

We study the heat transfer processes in the layered gypsum material at high temperatures. We consider the gypsum material with different layered plates in $\mathrm{x}$-direction: foam gypsum plate with the density $300 \mathrm{~kg} \cdot \mathrm{m}^{-3}$ and gypsum board with the density $1000 \mathrm{~kg} \cdot \mathrm{m}^{-3}$. The gypsum board on one border $x=L$ is heated with temperature $T=20+345 \lg (8 t / 60+1)^{\circ} \mathrm{C}$ (this equation simulates the burning temperature), where $t$ is the time in seconds. In one gypsum layer the heat and mass transfer process is analysed and described in [16;17]. 
The hybrid experimental numerical method is proposed in this paper. The specific heat $c_{p}$ and thermal conductivity $K$ coefficients depending on temperature $T$ are obtained: $K$ decreases from the value $0.24 \mathrm{~W} \cdot\left(\mathrm{m} \cdot{ }^{\circ} \mathrm{C}\right)^{-1}$ by $T=20^{\circ} \mathrm{C}$ to $0.12 \mathrm{~W} \cdot\left(\mathrm{m} \cdot{ }^{\circ} \mathrm{C}\right)^{-1}$ by $T=200{ }^{\circ} \mathrm{C}$, then $K$ increase is depending on $T$ value 0.24 ; coefficients $c_{p}$ in these heat intervals are increasing from $1000 \mathrm{~J} \cdot\left(\mathrm{kg} \cdot{ }^{\circ} \mathrm{C}\right)^{-1}$ by $T=20^{\circ} \mathrm{C}$ to $5500 \mathrm{~J} \cdot\left(\mathrm{kg} \cdot{ }^{\circ} \mathrm{C}\right)^{-1}$ and then decreasing to 1000 . The process of diffusion and heat transfer is considered in 1-D space domain

$$
\Omega=\{(x, y, z): 0 \leq x \leq L,-\infty \leq y \leq \infty,-\infty \leq z \leq \infty\} .
$$

The domain $\Omega$ consists of $\mathrm{N}$ layers medium $(N=1,2,3)$. We will consider the non-stationary problem for $\mathrm{N}$ layered piece-wise homogenous materials in the domain

$$
\Omega_{i}=\left\{(x, y, z): x \in\left(x_{i-1}, x_{i}\right), y \in(-\infty, \infty), z \in(-\infty, \infty)\right\}, i=\overline{1, N},
$$

where $H_{i}=x_{i}-x_{i-1}-$ the thickness of layer in $\Omega_{i}, x_{0}=0, x_{N}=L$.

The rate at which the temperature of the material changes in $N$ layers is determined bythe heat conduction PDE in the following form:

$$
\rho_{i} \frac{\partial T_{i}}{\partial t}=\frac{\partial}{\partial x}\left(\left(K_{i}(T) / c_{p i}(T)\right) \frac{\partial T_{i}}{\partial x}\right) ; x \in\left[x_{i-1}, x_{i}\right], i=\overline{1, N}, t \in\left[0, t_{b}\right],
$$

where $c_{p i}$-specific heat;

$K_{i}, \rho_{i}$ - heat conductivity and the density of the gypsum materialcorresponding;

$t_{f}$ - final time.

We assume that the coefficients $c_{p}, K$ in the PDEs are dependent on the temperature $T$ similarly [12] . Cubicspline was used for approximation $c_{p}, K$ (see Fig. 12 ), the density $\rho$ is taken as piece-wise constant in every layer.

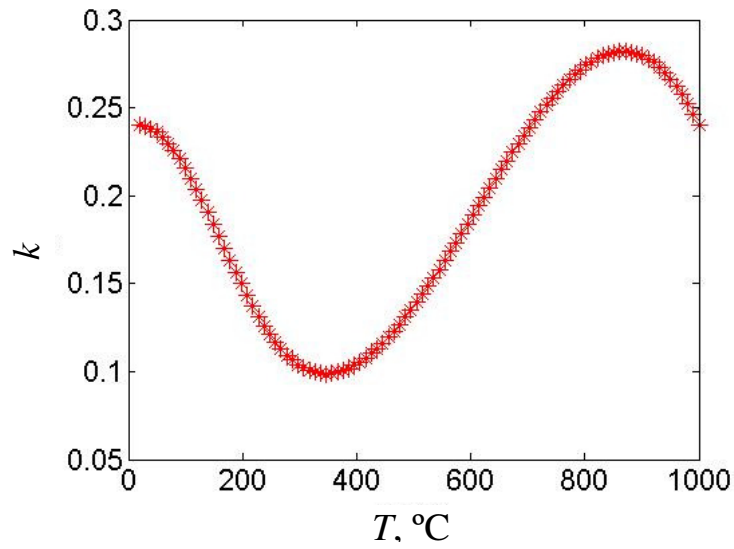

Fig. 1. Thermal conductivity $K$ dependence on temperature $T$

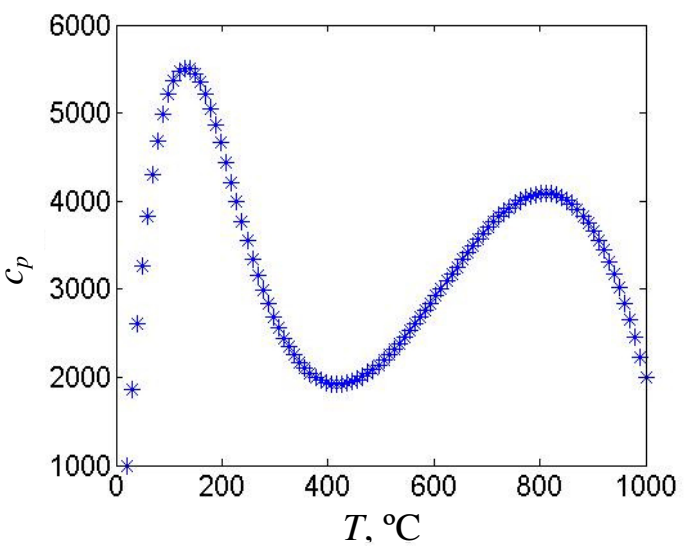

Fig. 2. Specific heat $c_{p}$ dependence on temperature $T$

The thermal diffusion coefficientsare defined as follows

$$
D_{i}(T)=\frac{K_{i}(T)}{\rho_{i} c_{p i}(T)}, i=\overline{1, N}
$$

in every layer depending on $T$. The initial condition for $t=0$ is taken as $T_{i}(x, 0)=T_{0}$, where $T_{0}=20^{\circ} \mathrm{C}$.

Then the following boundary and continuous conditions with discontinuous first order derivatives of temperature on intermediate layers $x_{i}, i=\overline{1, N-1}$ are used (2):

$$
\left\{\begin{array}{l}
\frac{\partial T_{1}(0, t)}{\partial x}=0, T_{N}(L, t)=T_{b}+T_{l}(t), \\
T_{i}\left(x_{i}, t\right)=T_{i+1}\left(x_{i}, t\right), D_{i}(T) \frac{\partial T_{i}\left(x_{i}, t\right)}{\partial x}=D_{i+1}(T) \frac{\partial T_{i+1}\left(x_{i}, t\right)}{\partial x}, i=\overline{1, N-1,}
\end{array}\right.
$$


where $T_{l}(t)=345 \lg (8 t / 60+1), T_{b}=20^{\circ} \mathrm{C}$.

In this case we can use the conservative averaging method (CAM). CAM for two layers with special integral splines with hyperbolic trigonometric functions allows reduce the problem (2) to an initial problem for the system of ODEs [18].

If the coefficients $c_{p}, K$ in the PDEs are continuous and only the density $\rho$ is piece-wise constant in every layer, then we have the first order derivatives continuous and the second order derivatives discontinuous in the equation (1). In both cases we can effectively use Matlab routine "pdepe" for solving initial-boundary value problems for parabolic-elliptic PDEs in the one space variable $\mathrm{x}$ and time t. The ordinary differential equations (ODEs) resulting from discretization in space are integrated to obtain approximate solutions at times. The integration of time is done with Matlab stiff solver "ode15s".

\section{The Matlab routine " pdepe"}

The routine solves PDEs of the following form $(u(x, t)=T(x, t))$ :

$$
c\left(x, t, u, \frac{\partial u}{\partial x}\right) \frac{\partial u}{\partial t}=\frac{\partial}{\partial x}\left(f\left(x, t, u, \frac{\partial u}{\partial x}\right)\right)+s\left(x, t, u, \frac{\partial u}{\partial x}\right),
$$

where $f$-flux term; $s$ - source term.

Discontinuities in $c, f$ and/or $s$ due to material interfaces are permitted provided that a mesh point is placed at each interface. form

For all $t$ and either $x=0$ or $x=L$, the solution components satisfy a boundary condition of the

$$
p(x, t, u)+q(x, t) f\left(x, t, u, \frac{\partial u}{\partial x}\right)=0
$$

In the call

sol = pdepe $(0$, pdefun, icfun, bcfun, xmesh, tspan $)$

pdefun computes the terms $c, f, s$ in the form $[\mathrm{c}, \mathrm{f}, \mathrm{s}]=$ pdefun $(\mathrm{x}, \mathrm{t}, \mathrm{u}, \mathrm{dudx})$,

icfun evaluates the initial conditions in the form $u=$ icfun $(x)$; when called with an argument $x$, icfun evaluates and returns the initial values of the solution components at $\mathrm{x}$ in the column vector, xmesh denote the $x$-mesh vector with xmesh(1) $=0$ and xmesh(end) $=\mathrm{L}$, tspan denote the $t$-mesh vector with tspan(1) $=0$ and $t \operatorname{span}($ end $)=t_{b}$, bcfun evaluates the terms $p$ and $q$ of the boundary conditions in the form

$[p l, q l, p r, q r]=\operatorname{bcfun}(x l, u l, x r, u r, t)$,

where $\mathrm{ul}-$ approximate solution at the left boundary $\mathrm{xl}=0$; ur - approximate solution at the right boundary $\mathrm{xr}=\mathrm{L}$;

$\mathrm{pl}$ and $\mathrm{ql}-$ column vectors corresponding to and evaluated at $\mathrm{xl}$, similarly $\mathrm{pr}$ and $\mathrm{qr}$ correspond to $\mathrm{xr}$.

pdepe returns the solution as a two dimensional array $\operatorname{sol}: u=\operatorname{sol}(:,:, 1)$ is an approximation to the solution $u$.

The element

$$
u(j, k)=\operatorname{sol}(j, k, 1)
$$

approximates $u$

$$
\text { at }(t, x)=(t \operatorname{span}(j), \operatorname{xmesh}(k)),
$$

$\mathrm{u}=\operatorname{sol}(j,:, 1)$ approximates the solution at time $\operatorname{tspan}(j)$ and mesh points $\operatorname{xmesh}(:)$. 


\section{Some numerical results}

For the numerical modelling $N_{t}=100$ time steps, $t_{b}=5000 \mathrm{~s}, N=50$ space steps are used. The solutions are obtained in the time with the maximal temperature $T\left(L, t_{b}\right)=994.47^{\circ} \mathrm{C}$. The results are obtained for $t_{1}=25 \mathrm{~min}, t_{2}=50 \mathrm{~min}, t_{3}=t_{b}=83.33 \mathrm{~min}=50000 \mathrm{~s}$.

The results of calculation forone layer of the gypsum board $\left(L=0.025 \mathrm{~m}, \rho=1000 \mathrm{~kg} \cdot \mathrm{m}^{-3}\right)$ are shown in Figs. $(3,4)$ with $T\left(0, t_{1}\right)=70.17^{\circ} \mathrm{C}, T\left(0, t_{2}\right)=208.6^{\circ} \mathrm{C}, T\left(0, t_{3}\right)=539.3^{\circ} \mathrm{C}$ (temperatures on another side of the layer).

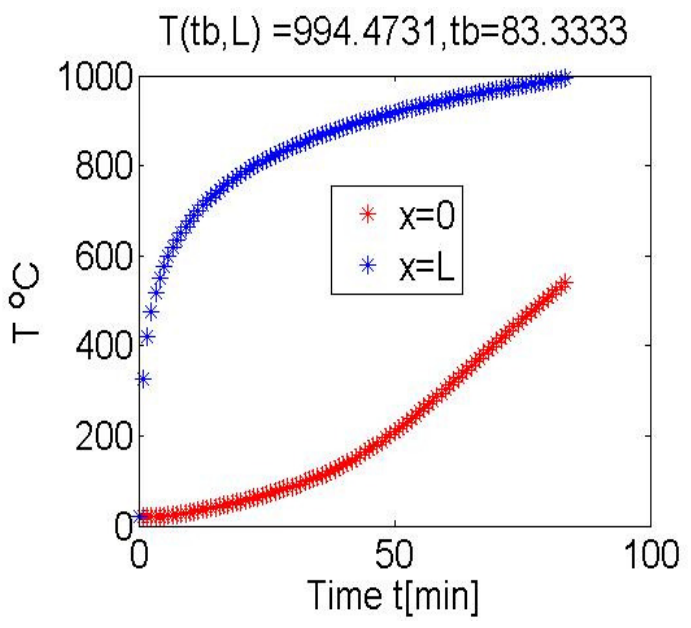

Fig. 3. Temperature $T(0, t)$ and $T(L, t)$ changes on surfaces depending on time $t$

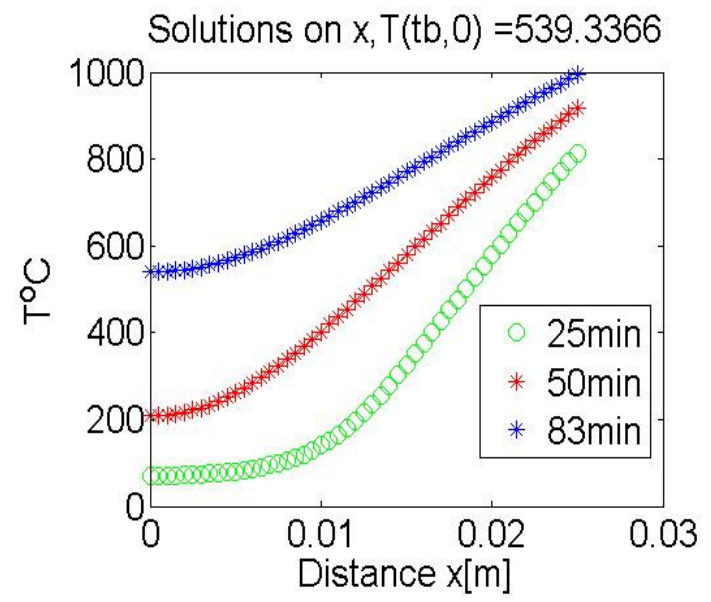

Fig. 4. Distribution of temperature $T$ over thickness of board at fixed time intervals

As shown in Fig. 3-4, after 50 minutes of burning at the gypsum plate on the other side the temperature will already exceed 200 degrees. In Fig. 5 the modeling and experimental results are compared for both surfaces at burning temperature $T(L, t) \in[476,861]^{\circ} \mathrm{C}$.

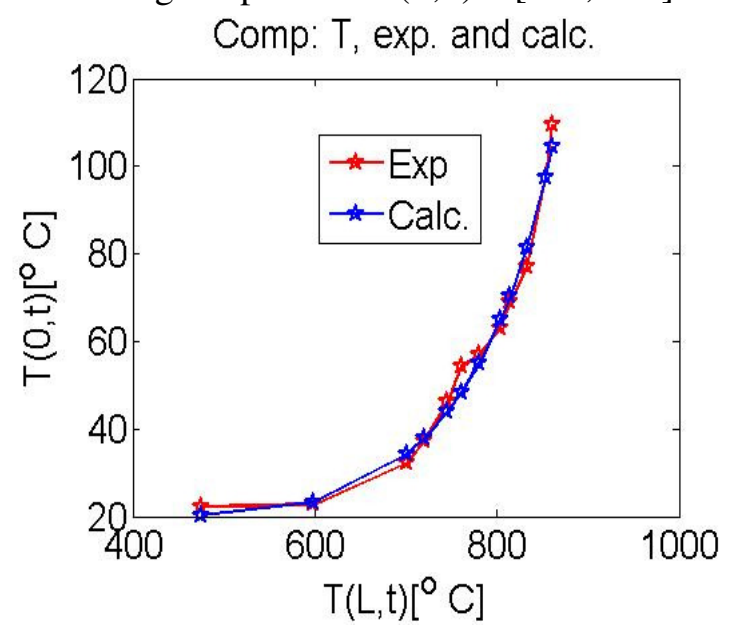

Fig. 5. Numerical and experimental results in one layer

For two layers with total thickness $L=0.025 \mathrm{~m}$ for foam gypsum plate $H_{1}=0.0125 \mathrm{~m}$ with density $\rho_{1}=300 \mathrm{~kg} \cdot \mathrm{m}^{-3}$ and gypsum board $H_{2}=0.0125 \mathrm{~m}$ with density $\rho_{2}=1000 \mathrm{~kg} \cdot \mathrm{m}^{-3}$, the results of numerical modeling are shown in Fig. 6 and 7 , where $T\left(0, t_{1}\right)=70.22^{\circ} \mathrm{C}, T\left(0, t_{2}\right)=199.9^{\circ} \mathrm{C}$, $T\left(0, t_{3}\right)=512.5^{\circ} \mathrm{C}$ (discontinuous first derivatives).

In Fig. 8 the numerical and experimental results are compared for $T(L, t) \in[476,902]^{\circ} \mathrm{C}$. In the case of continuous first derivatives we have for numerical results of $T(0, t)$ great difference from the experimental data: $T\left(0, t_{1}\right)=93.3{ }^{\circ} \mathrm{C}, T\left(0, t_{2}\right)=363.5^{\circ} \mathrm{C}, T\left(0, t_{3}\right)=818.3^{\circ} \mathrm{C}$ (see Fig. 9).

For the numerical experiment we use also backward orientation: for foam gypsum plate $H_{2}=0.0125 \mathrm{~m}$ with density $\rho_{2}=300 \mathrm{~kg} \cdot \mathrm{m}^{-3}$ gypsum board $H_{1}=0.0125 \mathrm{~m}$ with density $\rho_{2}=2000 \mathrm{~kg} \cdot \mathrm{m}^{-3}$. We have $T\left(0, t_{1}\right)=70.03{ }^{\circ} \mathrm{C}, T\left(0, t_{2}\right)=192.95{ }^{\circ} \mathrm{C}, T\left(0, t_{3}\right)=508.23{ }^{\circ} \mathrm{C}$ (the temperature for $x=0$ in this case is smaller also in direct orientation). 




Fig. 6. Temperature $\mathbf{T}(\mathbf{0 , t}), \mathbf{T}\left(\mathbf{H}_{1}, \mathbf{t}\right)$ and $\mathbf{T}(\mathbf{L}, \mathbf{t})$ changes depending on time $t$ in gypsum material consisting of two layers

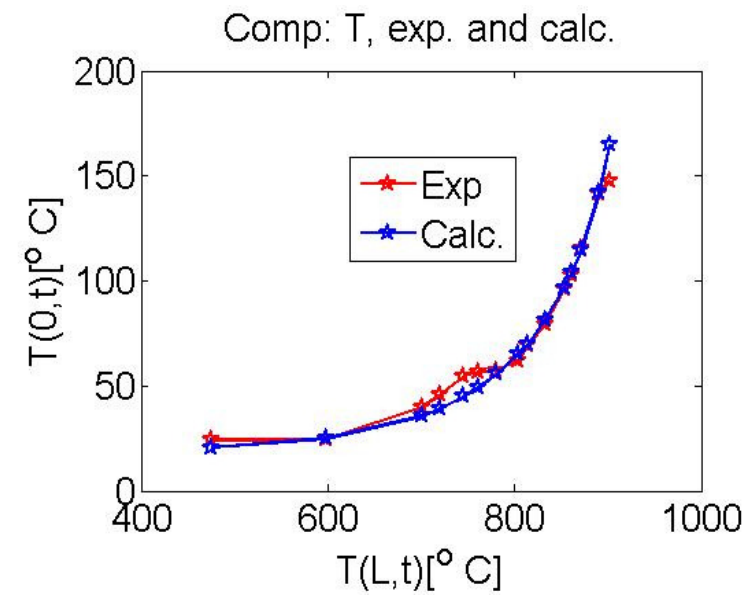

Fig. 8. Comparison of numerical and experimental results in gypsum material containing two different layers

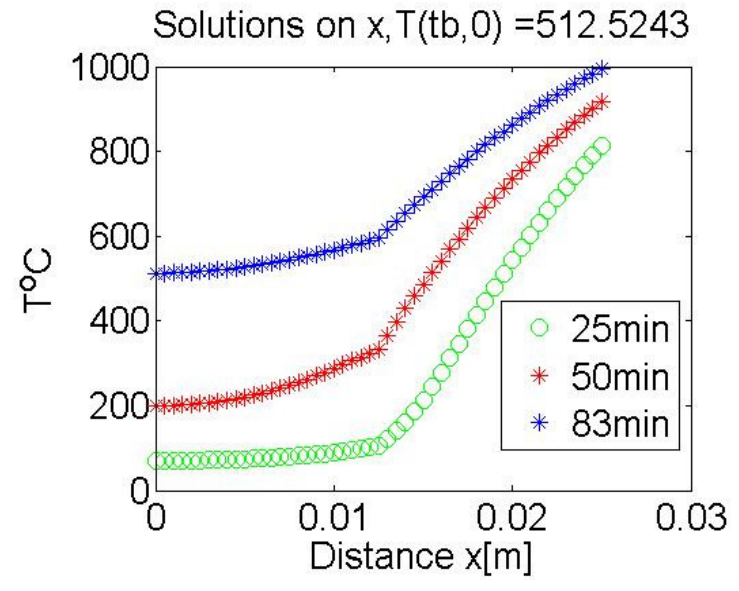

Fig. 7. Distribution of temperature $\mathbf{T}$ over thickness of gypsum material consisting of two layers at fixed time intervals

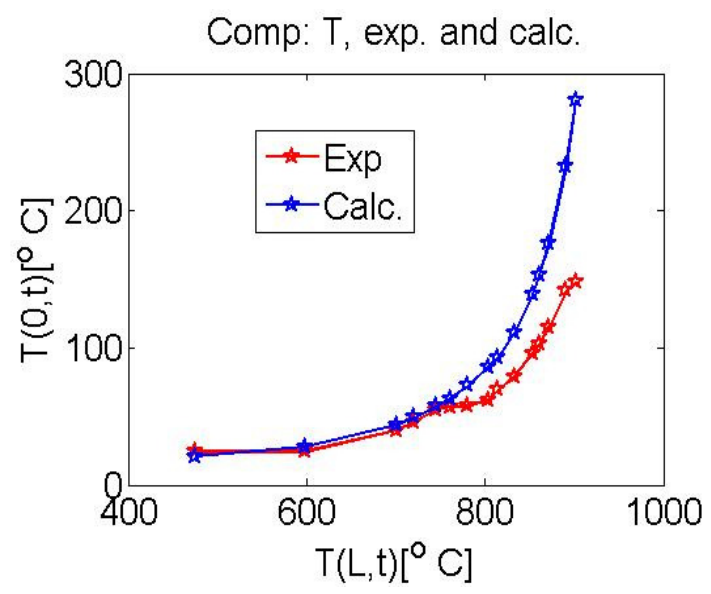

Fig. 9. Comparison of numerical and experimental results in gypsum material containing two different layers (continuous derivatives)

For three layers with total thickness $L=0.065 \mathrm{~m}$ for foam gypsum plates $H_{1}=0.026, H_{3}=0.026 \mathrm{~m}$ and gypsum board $H_{2}=0.013 \mathrm{~m}$ the results of calculation are presented in Fig. 10.

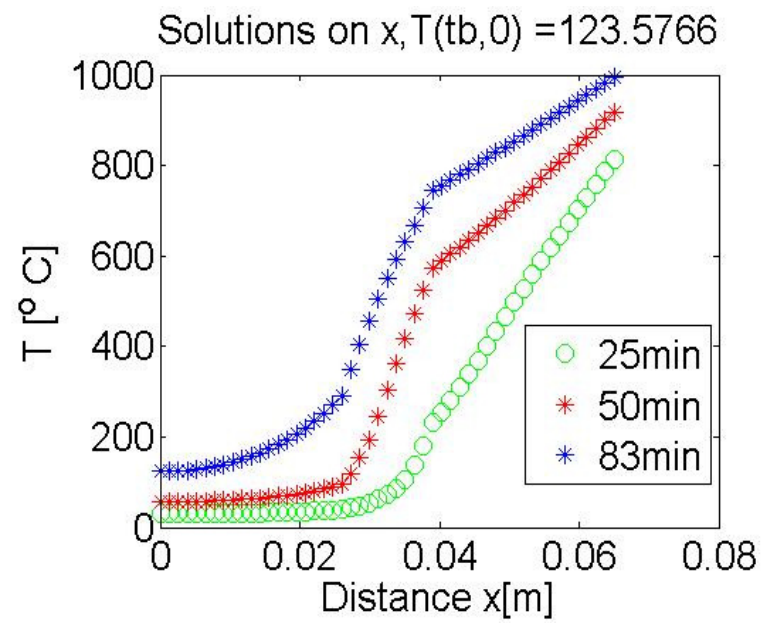

Fig. 10. Distribution of temperature $T$ over thickness of gypsum material consisting of three layers at fixed time intervals 
In Fig 10 it can be seen that $T\left(0, t_{1}\right)=29.55^{\circ} \mathrm{C}, T\left(0, t_{2}\right)=56.4{ }^{\circ} \mathrm{C}, T\left(0, t_{3}\right)=123.6^{\circ} \mathrm{C}$. Here it is good to see that the wall, which contains foam gypsum with a gypsum board in the middle well delayed fire spreading. After 50 min. of burning walls on one side, the other side of the wall would be only $56^{\circ} \mathrm{C}$. After $23 \mathrm{~min}$ (total time $83 \mathrm{~min}$ ) this temperature has risen more than 2 times to $123^{\circ} \mathrm{C}$.

\section{Conclusions}

1. For the heat transfer process modelling in gypsum layers the PDEs with coefficients of thermal conductivity and special heat dependence in temperature $\mathrm{T}$ are considered.

2. The corresponding initial boundary value problem approximation and calculation is based on the program package Matlab routine "pdepe" algorithm.

3. Proposed procedure allows to use a simple engineering algorithm for solving mass transfer equations for different substances in layered domain with different materials.

4. The results of numerical modelling give some new knowledge and physical interpretations about the drying process in layered gypsum material domain.

\section{Acknowledgments}

This work was partially supported by the European Regional Funding for a project SAM 1.1.1.1./A/16/004.

\section{References}

[1] Ang N., Wang C. The effect of water movement on specific heat of gypsum plasterboard in heat transfer analysis under natural fire exposure. Construction and Building Materials vol.18. 2004, pp. 505-515.

[2] Ghazi K., Hugi E., Wullschleger L., Frank T. Gypsum board in fire - modelling and experimental validation. Journal in Fire Science,vol.25, 2007, pp. 267-282.

[3] Ghazi K., Hugi E. Four types of gypsum plaster boards and their thermophysical properties under fire conditions. Journal in Fire Science,vol.27, 2008, pp. 27-43.

[4] Yu Q., Brouwers H. Thermal properties and microstructure of gypsum board and its dehydration products: A theoretical and experimental investigation. Fire and Materials,vol.36, 2012, pp. 573-589

[5] Skujans J., Vulans A., Iljins U., Aboltins A. Measurements of heat transfer of multi-layered wall construction with foam gypsum, Applied Thermal Engineering, vol.27 (7), 2007, pp. 1219-1224

[6] Skujans J., Iljins U. Ziemelis I., Gross U., Osītis N., Brencis R., Veinbergs A., Kukuts O. Experimental research of foam gypsum acoustic absorption and heat flow. In. Chemical Engineering Transactions, vol.19, pp. 79-84

[7] Oliver A., Thermal characterization of gypsum boards with PCM included: thermal energy storage in buildings through latent heat, Energy Build. vol. 48, 2012, pp. 1-7.

[8] Serrano S, Barreneche C., Fernández A., Farid M., Cabeza L., Composite gypsum containing fatty-ester PCM to be used as constructive system: thermophysical characterization of two shapestabilized formulations, Energy Build, vol.86, 2015, pp. 190-193.

[9] Borreguero A., Sánchez M., Valverde J., Carmona M., Rodríguez J., Thermal testing and numerical simulation of gypsum wall boards incorporated with different PCMs content, Appl. Energy, vol. 88, 2011, pp. 930-937.

[10] Sayyara M., Weerasiri R., Soroushiana P., Lu J., Experimental and numerical study of shapestable phase change nanocomposite toward energy-efficient building constructions, Energy Build., vol. 75, 2014, pp. 249-255.

[11]Lai C., Chen R., Lin C., Heat transfer and thermal storage behaviour of gypsum boards incorporating micro-encapsulated PCM, Energy Build. vol. 42, 2010, pp. 1259-1266.

[12] Wullschleger L., Wakili K., Numerical parameter study of the thermal behavior of a gypsum plaster board at fire temperatures, Fire and Materials, vol. 32, 2008, pp. 103-119.

[13] Kontogeorgos D., Founti M., Numerical investigation of simultaneous heat and mass transfer mechanisms occurring in a gypsum board exposed to fire conditions, Applied Thermal Engineering, vol. 30, 2010. pp.1461-1469. 
[14] Kolaitis D., Founti M. Development of a solid reaction kinetics gypsum dehydration model appropriate for CFD simulation of gypsum plasterboard wall assemblies exposed to fire, Fire Safety Journal, vol.58, 2013, pp. 151-159.

[15] Weber B. Heat transfer mechanisms and models for a gypsum board exposed to fire, International Journal of Heat and Mass Transfer, vol.55, 2012, pp. 1661-1678.

[16] Rahmanian I., Wang Y.C. A combined experimental and numerical method for extracting temperature-dependent thermal conductivity of gypsum boards. Construction and Building Materials, vol. 26, 2012, pp. 707-722.

[17] Benedikt Weber. Heat transfer mechanisms and models for a gypsum board exposed to fire. International Journal of Heat and Mass Transfer vol. 55, 2012 pp. 1661-1678.

[18] Aboltins A., Kalis H.,.Pulkis K.,Skujans J., Kangro I.. Mathematical modeling of heat transfer problem for two layered gypsum board products exposed to fire. Proceedings of International scientific conference "Engineering for Rural Development" Jelgava, 24.-26.05., 2017, pp. 1369-1376. 